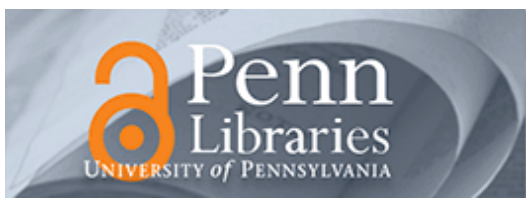

University of Pennsylvania ScholarlyCommons

Wharton Pension Research Council Working

Papers

Wharton Pension Research Council

$6-1-2012$

\title{
Valuing Variable Annuities with Guaranteed Minimum Lifetime Withdrawal Benefits
}

Petra Steinorth

St. John's University, steinorp@stjohns.edu

Olivia S. Mitchell

The Wharton School, University of Pennsylvania, mitchelo@wharton.upenn.edu

Follow this and additional works at: https://repository.upenn.edu/prc_papers

Part of the Economics Commons

Steinorth, Petra and Mitchell, Olivia S., "Valuing Variable Annuities with Guaranteed Minimum Lifetime Withdrawal Benefits" (2012). Wharton Pension Research Council Working Papers. 143.

https://repository.upenn.edu/prc_papers/143

This paper is posted at ScholarlyCommons. https://repository.upenn.edu/prc_papers/143

For more information, please contact repository@pobox.upenn.edu. 


\title{
Valuing Variable Annuities with Guaranteed Minimum Lifetime Withdrawal Benefits
}

\begin{abstract}
This paper examines variable annuities (VA) that include a guaranteed minimum withdrawal lifetime benefit (GWLB). For a risk-averse retiree, we show that the basic VA/GWLB is unlikely to induce systematic withdrawals early in retirement, while it also provides useful protection in the case of extreme longevity. The typical VA/GWLB increases utility compared to not annuitizing, though its money's worth ratio is slightly lower than not annuitizing. The individual's portfolio mix elected within the VA has the greatest impact on the valuation of the product, mattering much more than fees or mortality. Having a GWLB prompts riskier portfolio choices up to the point where insurers must restrict the risky share so as to protect solvency.
\end{abstract}

\section{Disciplines \\ Economics}




\title{
Valuing Variable Annuities with Guaranteed Minimum Lifetime Withdrawal Benefits
}

\author{
Petra Steinorth and Olivia S. Mitchell
}

June 2012

\author{
PRC WP2012-04 \\ Pension Research Council Working Paper \\ Pension Research Council \\ The Wharton School, University of Pennsylvania \\ 3620 Locust Walk, 3000 SH-DH \\ Philadelphia, PA 19104-6302 \\ Tel: 215.898.7620 Fax: 215.573.3418 \\ E-mail: prc@wharton.upenn.edu \\ http://www.pensionresearchcouncil.org
}

The researchers acknowledge support from the Boettner Center/Pension Research Council at The Wharton School of the University of Pennsylvania, and the TIAA-CREF Institute. They also appreciate comments provided by Benny Goodman, Michael Heller, Alexander Kling, Christian Knoller, Raimond Maurer, Richard Peter, David Richardson, and Stephen Utkus, though opinions and errors are solely those of the authors and not of the institutions with whom the authors are affiliated. (C) 2012 Steinorth and Mitchell. All rights reserved. 


\title{
Valuing Variable Annuities with \\ Guaranteed Minimum Lifetime Withdrawal Benefits
}

\begin{abstract}
$\underline{\text { Abstract }}$
This paper examines variable annuities (VA) that include a guaranteed minimum withdrawal lifetime benefit (GWLB). For a risk-averse retiree, we show that the basic VA/GWLB is unlikely to induce systematic withdrawals early in retirement, while it also provides useful protection in the case of extreme longevity. The typical VA/GWLB increases utility compared to not annuitizing, though its money's worth ratio is slightly lower than not annuitizing. The individual's portfolio mix elected within the VA has the greatest impact on the valuation of the product, mattering much more than fees or mortality. Having a GWLB prompts riskier portfolio choices up to the point where insurers must restrict the risky share so as to protect solvency.
\end{abstract}

\section{Petra Steinorth}

School of Risk Management, Insurance, and Actuarial Science

St. John's University

steinorp@stjohns.edu

\section{Olivia S. Mitchell}

Professor of Insurance/Risk Management \& Business Economics/Policy

University of Pennsylvania - The Wharton School

mitchelo@wharton.upenn.edu 


\section{Valuing Variable Annuities with Guaranteed Minimum Lifetime Withdrawal Benefits}

Petra Steinorth and Olivia S. Mitchell

A variable annuity (VA) provides retirees with both an insurance-protected retirement annuity and a flexibly-managed investment portfolio. ${ }^{1}$ Retirees value the annuity because it provides downside risk protection, while at the same time, holding equities offers exposure to possibly greater returns. Though some critics have cited complexity and high fees as disadvantages of the VA product, ${ }^{2}$ they remain quite popular among U.S. households. For instance, in Q1 2012, policyholders held \$1.61 trillion in VAs; new sales in Q4 2011, at \$36.2 billion, were almost double the volume of fixed annuity sales (\$16.9 billion; IRI (2012)). By the end of 2010, almost half (46\%) the assets in VAs belong to Baby Boomers making this cohort the largest owner of VAs, followed by current retirees $(35 \%))^{3}$ The fact that retirees and near-retirees hold such a substantial portion of their assets in VAs motivates the need to understand how to value these products.

Variable annuities in the U.S. typically include several guarantee features which may be purchased in addition to the lifetime payout stream. One such additional guarantee is the Guaranteed Minimum Withdrawal Benefit for Lifetime (GWLB) which offers the buyer lifetime income benefits while also allowing him to take flexible withdrawals. GWLBs permit a retiree to withdraw a certain percentage of his guarantee base for the remainder of his life; this base is usually defined as his initial investment in the product. Withdrawals in excess of the guaranteed withdrawal amount are possible, but they reduce the guarantee base. GWLBs are by far the most popular optional rider for VAs with living benefits: some $84 \%$ of all VAs include optional living benefits, and three-quarters of net premiums went to GWLBs (Q4:

\footnotetext{
${ }^{1}$ For further discussion on VA's, see, among others, Chai et al. (2011), Horneff et al. (2007; 2010a and b); Kartashov et al. (2011), and Milevsky and Posner (2001).

${ }^{2}$ See for instance Smartmoney.com (2011), and Orman (nd).

${ }^{3}$ See IRI (2010)).
} 
2009). Currently over $60 \%$ of all VA purchases include a GWLB (LIMRA 2010). In addition to being the most popular guarantee, the GWLB is also the only product that combines longevity protection with withdrawal flexibility, hence it is seen as a "second-generation" guarantee. Nevertheless, no research study has thus far examined whether and for whom the GWLB is most appealing.

Accordingly, in this paper we use a Money's Worth Ratio (MWR) approach to measure the expected payout of a variable annuity with a GWLB, and we also describe how a risk-averse decision maker would value such a product. In this effort, we follow prior analysts who have examined both MWR and utility valuations of simpler annuity products; ${ }^{4}$ our contribution is to embed the more complex GWLB into a utility setting. Optimal withdrawal patterns with VAs turn out to be quite complex, since each withdrawal may affect the account balance as well as the guarantee value in different ways, which, in turn shape possible future withdrawals. We also show that the optimal withdrawal strategy for a risk-averse expected utility maximizer must take into account the negative effect of consumption fluctuations against which the GWLB protects. ${ }^{5}$ To preview our findings, we show that the guaranteed withdrawals do not induce systematic withdrawals from the beginning, but instead they are used as a hedge against extreme longevity. In addition, the GWLB may induce excessive risktaking by retirees, which may become critical from the insurer's perspective.

Prior research on VAs has focused on actuarial aspects such as pricing and hedging of a variety of guarantee products in the VA space, including the Guaranteed Minimum Income Benefit (GMIB) which does provide lifetime income protection but generally does not allow flexible withdrawals in retirement. The Guaranteed Minimum Withdrawal Benefit (GMWB) feature does not include longevity protection, since withdrawals cease if the account value is zero and the guarantee value is withdrawn. The Guaranteed Minimum Account Benefits

\footnotetext{
${ }^{4}$ For recent work along these lines see the items cited in note 1 as well as Mitchell et al. (1999), James and Song (2001), Fong (2002), Doyle et al. (2004), Thorburn et al. (2007) and Fong et al. (2011).

${ }^{5}$ The Money's Worth Ratio evaluates expected cash flows, while an expected utility approach evaluates expected cash flows as well as the volatility of these flows.
} 
(GMAB) option ensures that the retiree's account value does not fall below a certain threshold net of withdrawals; nevertheless there is no lifetime income security (unless the account value is held in a traditional life annuity). Yet another feature on offer is the Guaranteed Minimum Death Benefits (GMDB) which secures a certain account value for the buyer's heirs, in the event of his death. Several analysts including Bauer et al. (2008) have developed actuarial pricing models to determine risk-neutral pricing of the types of guarantees often embedded in VA products. For instance, Milevsky and Posner (2001) and Ulm (2006) address GMDB pricing; Milevsky and Salisbury (2008) focus on GMWB pricing; and Holz et al. (2008) investigate whether GWLBs are priced actuarially fairly. Those studies differ from ours in that they explored actuarially fair pricing for additional or optional VA benefits by computing the expected costs of these optional benefits and transforming them into yearly account payments. By contrast, our goal is to investigate how risk-neutral and risk-averse consumers would be anticipated to value VA/GWLB structures compared to observed market prices for these products.

A few prior VA studies take a policyholder perspective, including Ulm (2010) who examined the impact of policyholder transfer behavior on GMDBs, and Brown and Poterba (2006) who explored policyholder characteristics. Also Charupat and Milevsky (2002) and Horneff et al. (2010a and b; 2011) examined asset allocations within variable annuities; Dai et al. (2008) and Kling et al. (2010) looked at optimal withdrawal strategies for VA investors in a risk-neutral framework. Dai and et al. (2008) also derived optimal behavior for withdrawing funds from a GMWB, while Kling et al. (2010) studied withdrawal behavior with GWLBs. Both of the latter studies used the withdrawal patterns they derived to determine pricing of these guarantees and hedging.

Our work takes a different approach in modeling the optimal withdrawal strategy for the VA context. First, we do not assume that individuals all maximize expected cash flows from their assets. Rather, since we focus on securing retirement income, we model risk-averse 
individuals who evaluate alternative portfolio options not only according to their expected returns but also according to their payoff volatility. An additional contribution of our paper is that we use an optimal withdrawal strategy to assess the appeal of offered products at market prices, rather than assessing actuarially fair market prices. In this, we follow Mitchell et al. (1999) and Horneff et al. (2007) who compute MWRs as well as expected utility measures of traditional fixed annuity products. Accordingly, we contribute to the literature by using this approach to investigate VA/GWLBs.

In what follows, we first develop our modeling approach. After explaining assumptions used for our simulations, we present and discuss results. To place our results in context, we compare the expected utility of the VA/GWLB options to an alternative portfolio invested outside the VA. ${ }^{6}$ The paper concludes with discussion of implications for insurers.

\section{Methodology}

We develop an expected utility setup to measure the impact of outcomes associated with a VA/GWLB product; the goal is to first show how a rational, risk-averse decisionmaker might value this product as a way to finance retirement. Accordingly, we posit that, at retirement, the individual determines what portion of his wealth will be consumed each period, with the remainder saved for later. Our approach compares consumer wellbeing including a VA/GWLB, with traditional investment choices excluding the annuity. To do so, we must first determine optimal withdrawals for the investment alternatives. For comparability, we assume that the same portfolio of investments alternatives is available and chosen both within and outside the VA. Next, we provide sensitivity analysis using a range of sensible parameters embedded in a life-cycle consumption/saving model. ${ }^{7}$ Additionally we

\footnotetext{
${ }^{6}$ Here we do not take into account taxes as we focus on the retirement period where tax differentials between VAs and direct investments play little role. Future work will address tax issues in more depth.

${ }^{7}$ C.f. Koh(1998), Viceira (2001), Gomes and Michaelides (2005), Chai et al. (2011), Kartashov et al. (2011), and Horneff et al. (2010a and b, 2009).
} 
offer sensitivity analysis with respect to the portfolio allocation, to account for differing portfolios in the VA/GWLB.

Deriving optimal consumption paths in the non-VA environment requires standard dynamic stochastic programming. Deriving optimal withdrawals for the VA/GWLB alternative are harder to determine, as both the future account values and also the values of the future guarantee are influenced by current consumption. Accordingly we postulate that the retiree maximizes expected utility over $T$ possible remaining periods of life. If preferences are constant over time, additively separable, and characterized by a utility function $u$ with $u>0$ and $u^{\prime \prime}<0$, the maximization problem takes the form:

$$
\max _{C_{1}, \ldots, C_{T}}\left[U\left(C_{1}, \ldots, C_{T}\right)=u\left(C_{1}\right)+E\left(u\left(C_{2}\right)\right)+\ldots+E\left(u\left(C_{T}\right)\right)\right] .
$$

Here $C_{t}$ with $t \in\{1,2, \ldots, T\}$ denotes consumption at each point in time $t$. The maximization problem is subject to a budget constraint displayed by:

$$
W_{t}-C_{t} \geq 0
$$

where $W_{t}$ denotes overall wealth at $t$. According to (2), the retiree cannot consume more than his current wealth level at any point in time, i.e. he cannot borrow against future income. Cash not consumed at date $t$ is invested in a mixed portfolio consisting of different assets that pay off according to a geometric Brownian motion process. Here the risky asset evolves according to:

$$
W_{t+1}=\left(W_{t}-C_{t}\right) \exp \left(\left(\mu-\sigma^{2} / 2\right)+\sigma Z_{t}\right)_{t}
$$

where $\mu$ denotes the drift of the Brownian motion, $\sigma$ the standard deviation of the chosen portfolio, and $Z_{t}$ the underlying Wiener process. Furthermore, we posit that there is no negative consumption, i.e. $C_{t}>0$ and initial wealth is positive, i.e. $W_{o}>0$ and never becomes negative, i.e. $W_{t} \geq 0 \quad \forall t \in\{1, \ldots, T\}$ where $T$ denotes the maximum years in retirement. 
Rewriting the optimization problem (1) by the according recursive Bellman equation, we obtain:

$$
V\left(W_{t}\right)=\max _{C_{t}}\left\{u\left(C_{t}\right)+E\left(V\left(W_{t+1}\right)\right)\right\}
$$

subject to (2) and (3) and the non-negativity constraints on the wealth level. Here $V$ denotes the value function which displays the expected utility of wealth level $W_{t}$ under the optimal consumption path. This leads to the standard life-cycle model for financing retirement, where the individual weighs consuming now versus later, given the level of initial wealth. ${ }^{8}$ Nonconsumed wealth is invested in a combined portfolio according to risk preferences, and the consumer can anticipate earning a stochastic return having a known mean and standard deviation. In the next period, resulting wealth is again allocated between consumption and saving. Accordingly, the optimal consumption path is described as follows:

$$
C_{t}^{*}=\arg \left[\max \left\{u\left(C_{t}\right)+E\left(V\left(W_{t}-C_{t},\right)\right)\right\}\right] .
$$

Adding a VA/GWLB to the analysis implies that the value function will now depend not only on actual wealth remaining, but also on the current guarantee value $G_{t}$. Therefore, the optimization problem changes to:

$$
V\left(W_{t}, G_{t}\right)=\max _{C_{t}}\left\{u\left(C_{t}\right)+E\left(V\left(W_{t+1}, G_{t+1}\right)\right)\right\} .
$$

In the simplest case, the guarantee evolves according to:

$$
G_{t+1}=G_{t} \cdot\left(1-\max \left(0,\left(C_{t}-G_{t} \cdot W A\right) / W_{t}\right)\right)
$$

Here the guaranteed withdrawal amount is usually the guarantee value times a predefined yearly withdrawal percentage $W A$. If the insured person were to withdraw more than the guaranteed amount, his guarantee value will be reduced by the ratio of the excess withdrawal to the current account value, on a pro rata basis. We will refer to this case as the "plain"

\section{VA/GWLB.}

\footnotetext{
${ }^{8}$ Retirement is characterized as a period of zero labor earnings with a specific amount of initial wealth available to invest at the beginning of the period.
} 
In the marketplace, GWLBs often include additional features that can increase the guarantee value over time, including step-ups/ratchets and roll-ups. ${ }^{9}$ The step-up or ratchet option boosts the guarantee if the account value exceeds the guarantee value at certain prespecified dates, usually the policy anniversary. The roll-up provides for a periodic and specified interest rate increase on the guarantee value; for instance a roll-up of 5\% implies that the guarantee value increases by $5 \%$ per year. The step-up/ratchet guarantee can be modeled by adjusting the guarantee process as follows:

$$
G_{t+1}=\max \left(W_{t+1}, G_{t} \cdot\left(1-\max \left(0,\left(C_{t}-G_{t} \cdot W A\right) / W_{t}\right)\right)\right) .
$$

We refer to this case as the ratchet VA/GWLB. A rollup leads to the following guarantee where $r$ denotes the roll-up interest rate:

$$
G_{t+1}=G_{t} \cdot\left(1-\max \left(0,\left(C_{t}-G_{t} \cdot W A\right) / W_{t}\right) \cdot(1+r)\right.
$$

Figure 1 illustrates how the guarantee base $G_{t}$ might evolve over time under a plain $\mathrm{VA} / \mathrm{GWLB}$ and a ratchet VA/GWLB, respectively, where the initial account value W0 and the guarantee base both equal $\$ 100,000$. The example illustrates a deterministic behavior where the policyholder always withdraws the guaranteed withdrawal, except in the fourth period where he makes an excess withdrawal of $\$ 10,000$. His account value peaks in period three due to favorable stock market developments. The left vertical axis depicts the guarantee base (dotted line) and account value (solid line) ranging from $\$ 85,000$ to $\$ 110,000$. The left vertical axis ranges from $\$ 0-\$ 10,000$ and displays actual (dark gray column) and guaranteed withdrawals (lighter gray column). Under the plain VA/GWLB, the favorable asset development in period three does not have an impact on the guarantee base, while it significantly increases the guarantee base under the ratchet VA/GWLB. The excess withdrawal in the fourth period decreases the guarantee base significantly under both

\footnotetext{
${ }^{9}$ See Kling et al. (2010).
} 
alternatives. However, the guarantee base under the ratchet VA/GWLB still exceeds the initial guarantee of $\$ 100,000$ due to the earlier step-up.

\section{Figure 1 here}

In such a setting, optimal consumption from the VA/GWLB is determined by balancing the effects of current consumption on the future account value; the latter may be used both to protect future consumption and the future guarantee value. Accordingly, the optimal consumption path is as follows:

$$
C_{t}^{*}=\arg \left[\max \left\{u\left(C_{t}\right)+E\left(V\left(W_{t}-C_{t}, G_{t+1}\left(C_{t}\right)\right)\right)\right\}\right] \text {. }
$$

In each period, the individual determines whether the value function in the next period is greater from consuming just the guaranteed withdrawal amount, versus consuming more or less. Even though the future guarantee value is reduced by doing so, consuming more than the guaranteed withdrawal amount might be optimal if the guaranteed withdrawal amount is relatively small compared to the current account value. Consuming more could also be appealing at very old ages, because there is less uncertainty about remaining life expectancy; in that case, the guarantee becomes less valuable even for a risk-averse individual.

The Money's Worth Ratio (MWR) of an annuity product is defined as the expected present discounted value of benefit flows relative to the purchase premium (Mitchell et al. 1999). We generate the optimal consumption streams using the computed optimal withdrawal strategies for both the VA/GWLB and for a non-VA regular investment approach; consumption flows are discounted using a term structure of interest rates. When $i_{k}$ denotes the interest rate in period $k$, the discount factor of one dollar invested at point in time $j$ at $h$ is equal to $1 /\left(1+i_{k}\right) \cdot \ldots \cdot\left(1+i_{h}\right)$. We define ${ }_{x} P_{j}$ as the probability that an $x$-year old person survives another $j$ years; then the MWR of an x-year old individual is equal to:

$$
\operatorname{MWR}\left(C_{1}, \ldots, C_{T}\right)=\sum_{j=1}^{T} \frac{C_{j}{ }_{x} P_{j}}{\prod_{k=1}^{j}\left(1+i_{k}\right)} .
$$


One could think of dividing the benefit flow from the VA/GWLB in each time period into two parts: one portion from the guarantee, and the second from consuming more than the guarantee. The guaranteed amount is discounted with a corporate BAA bond yield rate for as long as the guarantee is in effect, as commonly done to determine MWR for annuitized payments. Benefit flows above the guarantee are discounted by the rate of return of the chosen portfolio net of management fees, as the policyholder is directly exposed to any volatility in his chosen investment portfolio.

The MWR is useful in determining the expected value of the cash flow per premium dollar spent. Nevertheless, it does not take into account how a risk-averse decision maker will perceive the product, including the investment riskiness and the variability in consumption that such risk implies. Accordingly, we also compare MWR results with utility measures as defined in (1). The probability density function of possible consumption outcomes is determined using Monte-Carlo simulation.

\section{Simulation Parameters}

The simulations require us to make reasonable assumptions about preferences, capital market returns and volatility, and VA parameters; our choices of these are described next.

Individual Parameters. The simulations assume that a single 65-year old male enters retirement facing a mortality table defined by the 2000 Annuity Basic Mortality Table (SOA 1995). ${ }^{10}$ We use the Basic Table as it does not include margins or safety loadings, and we subsequently compare results with those using the U.S. Social Security Administration's 2006 cohort life table. ${ }^{11}$ If a retiree dies early, wealth remaining is assumed not to increase welfare as there is no bequest motive. In addition, we assume that the individual receives average

\footnotetext{
${ }^{10}$ This is the most recent annuity table widely used for pricing variable annuities We also assume that anyone still alive at 110 years of age will consume all of his remaining wealth.

${ }^{11}$ We use the 2006 cohort table as this is the most recent one available.
} 
Social Security benefits of about $\$ 13,000$ per year, ${ }^{12}$ and he holds $\$ 100,000$ in additional wealth at retirement which he either invests entirely in a VA/GWLB or in the capital market. ${ }^{13}$ Cash flows from these holdings are paid on top of Social Security benefits. Following the standard life cycle approach, we use an iso-elastic utility function $u(c)=\frac{c^{1-R R A}}{1-R R A}$ with a time discount factor $\beta=0.96$ and $\mathrm{RRA}=5 .^{14}$

Capital Market Parameters. To compare the returns from the two different portfolios, we assume that the individual holds the same mix of capital market assets irrespective of whether he buys a VA/GWLB or invests outside the VA. (We also conduct sensitivity analysis below, to account for different market environments and investment strategies. $)^{15}$ Accordingly, in both cases, the retiree selects a portfolio similar to that held by VA investors: $48.5 \%$ in equity, $22.2 \%$ in fixed income, $14.7 \%$ in balanced funds/hybrids, $11.5 \%$ in bonds, and $3.3 \%$ in money market assets (IRI (2010)). Assuming a 10\% return on equity, $6 \%$ on bonds, and $3 \%$ on safe investments, the average expected return gross of fees in the VA would then be about $6.75 \%$. Accordingly, the portfolio is modeled with $\mu=0.0675$ and $\sigma=0.18 .^{16}$ (We also offer sensitivity analysis varying $\mu$ and $\sigma$ below). Taking into account average fees for retail investments, we compute an annual investment charge of $1.26 \%$ for the average portfolio held outside the VA (IRI 2010).

To determine the optimal strategy for the non-VA investment, we use stochastic dynamic programming and compute the value function $V\left(W_{t}\right)=\max _{c_{t}}\left\{u\left(c_{t}\right)+E\left(V\left(W_{t}-C_{t}\right)\right\}\right.$.

\footnotetext{
${ }^{12}$ This corresponds to average annual Social Security income (SSA 2011).

${ }_{13}^{13}$ Poterba et al. (2012) report of $\$ 111,600$ in median financial assets for a two person household age 65-69.

${ }^{14}$ Assumptions on beta and RRA follow Horneff at al. (2009), and Pang and Warshawsky (2010).

${ }^{15}$ One could argue that the choice of the portfolio mix could be endogeneous as well as VAs allow different asset allocation. It is, however, industry practice to either substantially reduce the portfolio choices if a GWLB is chosen and companies mostly reserve the right to rebalance the chosen portfolio at any time if they fear that the chosen portfolio may make the guarantee to costly from their perspective. The exact information how and how often portfolios are rebalanced seems to be patented trade secrets and is not publicly available. See Abbott et al. (2009). Accordingly, the real life products seem to have significant restrictions when it comes to portfolio choice. Therefore, we refrain from making the portfolio choice endogenous and use average portfolio choices in VAs.

${ }^{16}$ These parameters compare to those used by Milevsky and Salisbury (2008), Maurer et al. (2009), and Kling et al. (2010). All calculations are nominal.
} 
We do this by discretizing the state space, ${ }^{17}$ and we solve the problem by backward induction, knowing that at the last possible age $T$, it will be optimal to fully consume all remaining wealth (i.e. $c_{T}=W_{T}$ ). Using this information, we compute the values of the value function on the predefined grid; next, we back up a period and again determine optimal consumption for using information on the value function from the next period. These steps are repeated until the first period is reached. Next, we simulate 20,000 Monte Carlo paths for the portfolio and mortality processes. Optimal consumption for each path at each point in time is computed using the value function until all sample individuals are simulated to die. If sample individuals run out of assets when no longevity protection is purchased, we assume that their only source of consumption is derived from social security benefits. Finally, using these data, we calculate the MWR and also the expected utility for the non-VA investment.

VA Parameters. To model the annuity product, we first assume that yearly expenses for the plain VA without any additional guarantees equal the U.S. product average. The IRI (2010) reported average VA fees of $2.43 \%$ in 2009 , which consisted of mortality and expenses (M\&E), administrative and distribution, and investment management fees. The IRI (2010) also published extensive data on fees by investment class, which we used to calculate a weighted VA annual fee of $2.47 \%$ of the account value (IRI (2010)). In this calculation, 1.24 percentage points or 124 basis points (bps) are attributable to M\&E fees, 18 bps to administrative and distribution fees, and the remaining $105 \mathrm{bps}$ to investment changes. Accordingly, investment management charges are below those for retail purchasers, but VA buyers do pay substantial M\&E fees. ${ }^{18}$ Data available for 2010 were less extensive, but we do know that the average fee dropped from 243 to $233 \mathrm{bps}$, where M\&E and administration fees accounted for $118 \mathrm{bps}$. Hence we adjusted the fees for the weighted investment by the same

\footnotetext{
${ }^{17}$ For the grid choice, we use triangular numbers which implies a convex choice of grid points as a higher degree of precision is more important for lower values. Results are slightly improved when using triangular versus an equidistant grid.

${ }^{18}$ IRI (2010) indicates that M\&E fees provide a VA buyer the option to annuitize the account value at a rate set at the beginning of the contract, a standard death benefit, and a promise that insurance charges will not increase.
} 
percentage decline, and we set the base case fee in the modeled VA to $237 \mathrm{bps}$. As fees do vary significantly among different providers, we also conduct sensitivity analysis with respect to the $\mathrm{M} \& \mathrm{E}$ and administrative charges. $\mathrm{M} \& \mathrm{E}$ and administration fees in the market range from 10-180 bps, so parameters for the sensitivity analysis vary from 129 to $280 \mathrm{bps}$.

To determine the additional cost of the GWLB, we sought out online prospectuses for 25 U.S. insurers having the most new VA sales (in 2011: Q1). Four had no online prospectus; of the remaining 21 companies, five did not offer a GWLB, and one company only offered group VAs. As ratchets are the most common GWLB enhancement, we restrict analysis to the plain guarantee as in (6) and the ratchet as in (7). The average fee for a GWLB having a $5 \%$ withdrawal at age 65 is $0.98 \%$; this corresponds to Morningstar Annuity Research Center Reports (2010: Q4) average fees of $0.99 \%$ for the GWLB in 2010. We found only one company explicitly indicating the price differential of $0.25 \%$ between a GWLB with and without a step-up. As this company offered a GWLB with step-up at $1 \%$, very close to the average price, we set the price for the step-up GWLB feature at $1 \%$, while the plain GWLB is assumed to cost $0.75 \%$.

To determine how consumers might value this complex product, we again compute the value function by backward induction, using the same grid points for the account value state space. Now, however, the value function is multivariate, depending on the retiree's account value as well as his guarantee value. ${ }^{19}$ In the last period, it is optimal to consume the greater of the account value and the guaranteed benefit from the VA/GWLB; this yields the multivariate value function for the last period. Next we go back a period to compute the value function and the optimal consumption of the prior period using information obtained for the final time point; we then repeat these steps until arriving at the first period. As before, we also conduct 20,000 Monte-Carlo simulations for the evolution of the assets as well as the mortality process. Information on optimal consumption patterns is obtained from the value

\footnotetext{
${ }^{19}$ As before, for the account value, grid points for the guarantee are set on average for every $\$ 2,000$.
} 
function, and these 20,000 paths are used to determine expected utility and MWRs under the two different guarantee options.

\section{Simulation Results}

In what follows, we first explore optimal withdrawals for retirees holding no variable annuity. We then analyze withdrawals for holders of a VA, and we complete the discussion for buyers of a VA/GLMB product.

Optimal Withdrawal Behavior for the Investor with No Annuity. Figure 2 illustrates the average consumption path conditional on survival that period, for all three portfolio alternatives (Investment only, plain VA/GWLB, and ratchet VA/GWLB). Not holding a VA/GWLB leads to higher consumption rates during the first 15 and 22 years (age 80 and 87) when compared to a plain VA and a ratchet VA, respectively. The VA/GWLB alternative has a penalty for excess withdrawals; this is most influential for early excess withdrawals as the guarantee base is reduced for the remaining lifetime. ${ }^{20}$ This is not the case for the non-VA investment, so individuals withdraw more in the beginning.

Figure 2 here

We display the standard deviation of consumption among surviving individuals in Figure 3. The retiree lacking an annuity, consumption volatility is projected to rise dramatically over the first two decades of retirement which will be unappealing to risk-averse individuals. Volatility declines significantly after 20 years (beginning at age 85) as more and more individuals outlive their assets. This effect starts to outweigh the fact that some individuals are quite well off because of favorable investment returns. Volatility vanishes towards the end, as all surviving individuals have outlived their assets. While there are some who experience very high consumption due to very positive capital market returns, it is still

\footnotetext{
${ }^{20}$ Even though it can catch up under the ratchet.
} 
true that an increasing number of individuals has little or no assets left; at some point variance in consumption declines to zero, as all rely completely on Social Security.

Figure 3 here

Optimal Withdrawal Behavior for the Buyer of a plain VA/GWLB. Figure 2 illustrates that, at the beginning, mean withdrawals rates on average are significantly higher than guaranteed withdrawals. For this reason, the guaranteed withdrawal profile is too low to induce systematic withdrawals in the early years. At the same time, owning a plain VA/GWLB reduces average consumption during the early years, in favor of greater consumption later compared to the retiree lacking a plain VA/GWLB. Figure 3 shows that the standard deviation of consumption at each point in time is lower for the plain VA/GWLB buyer, during his first three decades in retirement, compared to not having the plain VA/GWLB; this difference is largest after approximately 15 years (age 80). Figure 3 also shows that the longevity protection in the later years has an important impact on consumption volatility: volatility is greater than under the investment-only alternative, and it does not fall below $\$ 1,500$ standard deviation. This indicates that consumption at very old ages still varies importantly, which can be attributed to differing levels of guarantee base reductions due to earlier consumption, as well as to the fact that some individuals totally deplete their guarantee basis and account values, rendering them fully reliant on social security benefits.

In Figure 4 we illustrate the likelihood of making an excess withdrawal, i.e. withdrawing more than guaranteed withdrawal amount over time. With the plain VA/GWLB, we see that the guaranteed withdrawal of $5 \%$ of the guarantee base is not very appealing early in the retirement period. But the probability of exceeding the guaranteed withdrawals increases substantially with age and becomes greater than $90 \%$ after 36 years out in retirement or, i.e. after age 101. This demonstrates that individuals mostly use the plain VA/GWLB a buffer or last resort to protect against extreme longevity. They take early excess withdrawals to significantly reduce the guarantee base and then rely on the guaranteed benefit after the 
account value has been mostly depleted or previous investments turned out poorly. Accordingly, the GWLB does not induce systematic withdrawals from the beginning. Instead, it is used as a downside risk protection against longevity risk and bad market results.

Figure 4 here

Optimal Withdrawal Behavior for the Buyer of a Ratchet VA/GWLB. Figure 2 also displays average consumption for a ratchet VA/GWLB, conditional on survival. Overall, the ratchet reenforces the effects of the VA/GWLB in many regards. That is, the ratchet reduces early consumption slightly more than the plain VA/GWLB. At the same time, average consumption remains greatest under the ratchet VA/GWLB starting in year 14 after retirement (age 79) which is, of course, a beneficial feature of the ratchet. Figure 3 displays the volatility of consumption for the ratchet VA/GWLB; this tracks that of the plain VA/GWLB over time. It is worth noting, nevertheless, that it remains slightly lower over the lifetime, an outcome that should appeal to a risk-averse retiree. This might seem surprising, as the guaranteed withdrawals under a ratchet VA/GWLB depend not only on earlier withdrawals but also on past investment performance, which would be thought to increase the volatility of the guarantee base and withdrawals.

The probability of making an excess withdrawal is depicted in Figure 5. Under both VA/GWLB types, all individuals withdraw in excess of the guaranteed amount in the first period. The likelihood of withdrawing excessively decreases substantially over the lifetime and is close to zero at the end. The probability of making an excess withdrawal is always smaller under the ratchet VA/GWLB, because making guaranteed withdrawals becomes more attractive after the guarantee base is stepped-up. It is also worth noting that the ratchet VA/GWLB has the lowest volatility for the first 20 years (age 85, see Figure 4), though the volatility becomes higher than without the ratchet after that point. Even though average consumption is still very high in later years, some individuals have very high consumption levels while others do not receive very high payouts from their VA anymore. This is 
unappealing to a risk-averse retiree, while the higher consumption on average and the lower variation of average consumption over time are beneficial to the VA/GWLB investor.

Figure 5 here

Comparing Money's Worth Ratios and Utility of these Portfolios. To value the alternatives more formally, next we calculate the MWRs using equation (10). For the guaranteed withdrawal, we use the corporate BAA bond return for discounting. For the investor who does not hold the VA, the discount rate is the return on his portfolio minus fees for such an investment.

For the MWR analysis, we assume that the remaining account value represents the death benefit and discount it with the risky return rate (since the remaining account value depends solely on the portfolio development and earlier withdrawals). ${ }^{21}$ In case of the investor without a VA, we consider his remaining account value to be the death benefit (if any).

As the discount rates for the risky portion of the portfolio, we use the anticipated portfolio return rates minus fees for the non-VA investment, which sets the MWR for the investor without a VA to 1.0. We do this to increase comparability for the VA and non-VA investment. Accordingly, we interpret any divergence in MWRs from 1 in the VA/GWLB product to illustrate how the higher fees compare to the net returns the investor could have earned outside the VA. With respect to this benchmark, we find that the MWR of the plain VA/GWLB equals 0.89: this implies that for every dollar invested, an individual could expect to receive 89 cents in benefits. In other words, 11 cents per dollar are devoted to the protections embedded in the plain VA/GWLB and any loads charged, compared to an equally risky non-annuity investment. ${ }^{22}$ For the ratchet VA/GWLB, the MWR is one cent greater per

\footnotetext{
${ }^{21}$ It is worth noting that VAs frequently offer a death benefit which guarantees that when the retiree dies, the heirs will receive the greater of the current account value or the principal investment minus withdrawals. This enhanced death benefit is only offered until lifetime withdrawals are made, which usually commence after the second withdrawal from the contract.

${ }^{22}$ We treat the equity portfolio and the VA/GWLB investments as if they were equally risky, even though the included guarantee within the GWLB might have an impact on the overall portfolio exposure. But as we assume that both investments are in the same asset class, we use the same discount factors. This also offers us the possibility of explicitly determining the price for the included guarantee.
} 
dollar premium, or 0.90 . This reduction is less than the fee of $0.25 \%$ ( $25 \mathrm{bps}$ ) and it is the result of different withdrawal paths. Accordingly, adding a ratchet at 25 bps may be slightly underpriced.

The MWR figures do not take into account the insurance value of the VAs to riskaverse investors. Accordingly, Table 1 reports the Annuity Equivalent Wealth (AEW) levels of the different portfolio alternatives. The AEW is a measure of how much non-annuitized wealth would make an individual lacking access to an annuity would be willing to pay to purchase the VA product. Both VA/GWLB products offer higher AEW than the initial investment of $\$ 100,000$. The AEW of the plain VA/GWLB is roughly $\$ 107,000$ meaning that having $\$ 100,000$ in a plain VA/GWLB gives the same expected utility than $\$ 107,000$ under the investment only alternative. This indicates that the longevity protection of the GWLB is worth more to the risk-averse retiree than the loss of 11 cents per dollar in the terms of the MWRs. However, we also note that the difference in expected utility is not large $(7 \%$ difference) indicating that pricing is close to making individuals indifferent between the plain VA/GWLB and the investment only alternative. Accordingly, insurance companies are aware of the offered protection in a plain VA/GWLB and seek to extract a rent from the risk averse insured. The ratchet VA/GWLB increases the AEW to roughly $\$ 114,000$. Our prior examination of the consumption patterns under a ratchet VA/GWLB showed that the ratchet VA/GWLB had the lowest drop in consumption and a consistently smallest volatility over time. These patterns make the ratchet a beneficial feature of a VA/GWLB for a risk averse retiree. The ratchet VA/GWLB accordingly induces consumption patterns closest to an optimally smooth consumption.

Table 1 here

For the sake of comparison, we also compute expected utility for a single-premium, immediate annuity (SPIA) with either a $\$ 6,950$ or $\$ 7,950$ monthly payment. The Annuitant Mortality Table used in our analysis shows that a fair annuity without any transaction costs 
would return $8.618 \$$ annually per $100,000 \$$ invested. We derive the higher number by multiplying the fair annuity pay-out of $\$ 8,618$ by the average MWR for annuitants' mortality rates from Mitchell et al. (1999) and arrive at an annual pay-out of $\$ 7,950$. Actual current quotes indicate suggest that a 65 year old male receives a $\$ 6,950$ yearly annuity payment (in 2012). The SPIA paying $\$ 6,950 /$ month has a MWR of 80 cents per dollar invested (10 cents less than the ratchet VA/GWLB), but it increases the AEW to roughly $\$ 135,000$ - or $\$ 28,000$ more than the plain VA/GWLB and $\$ 21,000$ more than the ratchet VA/GWLB. The SPIA paying $\$ 7,950$ also has a higher MWR than the ratchet VA/GWLB, and its AEW equals roughly $\$ 165,000$ or more than $40 \%$ more than the ratchet VA/GWLB. Accordingly, a VA/GWLB combination does offer a higher expected utility than investment only alternative. Still, the traditional SPIA appears to be a more attractive product than the VA/GWLB options examined here.

\section{Sensitivity analysis}

To assess the sustainability of our results, we conducted sensitivity analyses with respect to three different dimensions of parameter variations: VA fees, capital market assumptions and mortality experience. The base case is always the set-up with the annuitants mortality, average VA fees of $237 \mathrm{bps}$, and $\mu=0.0675$ and $\sigma=0.18$.

Fees. As noted above, some have mentioned high fees as a problem peculiar to variable annuities. ${ }^{23}$ Hence it seems natural to investigate how much buying a particularly inexpensive, or expensive product, could change the consumer's valuation of a VA/GWLB. Accordingly, the sensitivity analyses explore what happens if an annuitant selected either the most or the least expensive VA available in the market. This leads us to decrease the account and

\footnotetext{
${ }^{23}$ See, e.g. http://www.smartmoney.com/retirement/planning/whats-wrong-with-variable-annuities9512/?zone=intromessage. The SEC provides the following note of caution about VAs under their investor tips page: "Caution: You will pay for each benefit provided by your variable annuity. Be sure you understand the charges. Carefully consider whether you need the benefit. If you do, consider whether you can buy the benefit more cheaply as part of the variable annuity or separately (e.g., through a long-term care insurance policy), see http://www.sec.gov/investor/pubs/varannty.htm. “
} 
investment fees to 129 bps (lowest-cost product found in the online market) and increase them to 280 bps (most expensive), leaving the GWLB rider fee untouched. ${ }^{24}$ Not surprisingly, higher fees reduce the MWRs as well as the expected utility for the plain VA/GWLB as well as the ratchet VA/GWLB (Table 2). The difference in expected utility between the highest and lowest fee is in the 5\% range, which is far less than the difference in utility between the base case and the life annuity. Changing fees impacts the drift of the Brownian motion $\mu$ which does not only impact the value of the VA/GWLB but also the optimal withdrawal behavior. The results should not depend on the reasons why the drift changes, i.e., whether the change in drift depends on different fee assumptions or a change capital market environment. We therefore discuss the qualitative impact of different fee assumptions on withdrawal behavior in the next session where we describe the sensitivity of the results due to changing capital market parameters.

Table 2 here

Capital market assumptions. Investors are in fact free to build their portfolios under the offered investment choices, ${ }^{25}$ so next we conduct sensitivity analysis with respect to capital market parameters. Specifically, we vary the values of drift $\mu$ from 0.04 to 0.10 , and $\sigma$ from 0.10 to 0.25 . Table 3 shows the expected utility and MWRs for the different portfolio combinations.

Table 3 here

For these different portfolio scenarios, we find that the AEW is greater for the ratchet VA/GWLB compared to the plain product. Thus a ratchet priced at 25 bps is a valuable addition to a VA/GWLB from the consumer's perspective. The MWR is mostly smaller under the plain product; however, it is greater for the two alternatives with the smallest variance, $\sigma=0.10$. Accordingly, the net present value of a ratchet increases for an increase in volatility

\footnotetext{
${ }^{24}$ Assuming that providers with higher/lower account fees also charge higher/lower GWLB and investment fees would lead to an even greater fee range.

${ }^{25}$ Which may, nevertheless, be restricted. See the discussion regarding insurer solvency below.
} 
and becomes positive as portfolio volatility approaches 0.18 . Logically, the portfolio must be sufficiently volatile in order for the ratchet to pay off. The difference between the MWR of the plain versus the ratchet product widens as the variance further increases. For the highest $\mu$ and $\sigma$, the difference in MWRs between the plain and the ratchet VA/GWLB exceeds seven percent, or seven cents per dollar invested.

From the insurer's perspective, the buyer's portfolio choice can have a substantial impact on the profitability of the VA/GWLB. The highest return/volatility portfolio under the ratchet has a MWR that slightly exceeds one and would therefore imply a loss for the insurance company. At the same time, the product offers a higher expected utility for the policyholder than the base case scenario with $\mu=0.0675$ and $\sigma=0.18$. Accordingly, insurers may actually be at risk that individuals will increase risk and return in their portfolios to the point that the guarantee becomes unprofitable for the insurer. This may be of particular interest in the current highly volatile market environment. A close examination of actual prospectus of offered ratchet VA/GWLBs shows that investment choices are usually restricted for GWLB buyers. ${ }^{26}$

We also find that an increase in the drift $\mu$ for a given $\sigma$ always increases the MWR; the expected utility also rises as the expected portfolio return increases. A higher $\sigma$ also boosts the MWR, since the GWLB provides downside risk protection. Individuals benefit more from upside risk in terms of average account values with higher volatility, while

\footnotetext{
${ }^{26}$ For instance in the Allianz Connection Variable Annuity, the prospectus states that "If you select this benefit [the GWLB], we restrict your Investment options and rebalance your portfolio quarterly. [...]. These restrictions support the benefit's guarantee and [...] they may limit the upside potential." (Allianz 2012, p. 46). The Prudential Premier Advisor Variable Annuity prospectus states that "Each living benefit requires your participation in a predetermined mathematical formula that may transfer your account value between the Subaccounts you have chosen from among those we permit with the benefit (i.e., the "permitted Sub-accounts") and certain bond portfolio Sub-accounts of AST. [...] Although not guaranteed, the optional living benefit investment requirements and the applicable formula are designed to reduce the difference between your Account Value and our liability under the benefit. Minimizing such difference generally benefits us by decreasing the risk that we will use our own assets to make benefit payments to you. Though the investment requirements and formulas are designed to reduce risk, they do not guarantee any appreciation of your Account Value. In fact, they could mean that you miss appreciation opportunities in other investment options.” (Prudential 2012, p. 47)
} 
downside risk is to some extent buffered by the GWLB. This is particularly the case for the ratchet VA/GWLB as a higher volatility increases the probability of a significant step-up.

However, our computations show that a higher $\sigma$ for a given $\mu$ does not always increase AEW as well as the MWR. Without the ratchet, a higher $\sigma$ at the lowest assumed drift is always beneficial: the chance to participate in upside risk is relatively appealing, compared to the return of the simpler VA portfolio. In the base case scenario with $\mu=$ 0.0675 , we see that expected utility is lower when $\sigma$ is reduced or increased compared to the base case value of $\sigma=0.18$. This shows that for the given $\mu=0.0675$, investors choose a close-to-optimal portfolio volatility. This is also an indicator that the chosen model seems to be a good fit for individual behavior. For the highest drift $\mu=0.10$, we see that a higher volatility increases the MWR but decreases AEW; this indicates, given the relative high returns in the VA portfolio, that downside risk protection no longer outweighs the gain due to high returns.

For the ratchet VA/GWLB, increasing the volatility for a given drift increases both the MWR and the AEW of the retiree for the observed scenarios. But differences in AEW become smaller when the volatility is already higher. Accordingly, we suppose that there will be a finite optimal volatility for any given $\mu$ which is just greater than $\sigma=0.25$. Again, this indicates that the ratchet VA/GWLB leads to riskier portfolios. Nonetheless, the combination of the highest return and volatility, i.e. $\mu=0.10$ and $\sigma=0.25$, gives higher AEW than the base case which indicates that investors should increase portfolio risk and return compared to the observed parameters that indicate the base case. Differences in AEW between the different portfolios are much greater than observed differences for fee variations. The best VA/GWLB portfolio in terms of AEW (ratchet with highest risk and return) fares only $6 \%$ worse than the more expensive SPIA. Accordingly, this ratchet VA/GWLB under the cheapest fees assumption could be nearly as good as the more expensive annuity. Yet as 
argued previously, it is unlikely that such a portfolio will be offered to VA/GWLB investors, as it would not be sustainable from the insurer's perspective.

Panel A of Figure 5 shows average consumption under the different market scenarios for the plain VA/GWLB. We display only four (of nine) different capital market scenarios, and set the base case as $\mu=0.0675$ and $\sigma=0.18$, to compare with the same return with higher volatility, i.e. $\mu=0.0675$ and $\sigma=0.25$. Given current capital market conditions, we compare these to the two alternatives with the same volatility but lower drift, i.e. $\mu=0.04$, $\sigma=0.18, \sigma=0.25$. A higher drift $\mu$ for a given $\sigma$ increases early consumption, while later consumption falls. This has essentially the same impact as decreasing fees, explained previously. At the same time, an increase in volatility $\sigma$ for a given drift $\mu$ leads to slightly lower consumption in the first years as the specifications from the utility function implies that individuals are prudent. Accordingly, a higher $\sigma$ increases precautionary savings. At the same time, a higher $\sigma$ makes the guarantee more attractive as the guarantee base is not impacted by the volatility.

Figure 5 here

Panel B of Figure 5 shows average consumption profiles under the different market scenarios for the ratchet VA/GWLB. Consumption patterns are mostly comparable to the plain product; and again, a higher $\operatorname{drift} \mu$ for a given $\sigma$ increases consumption during the first 20-25 retirement years, (until age 85-90) while average consumption is less after this period. A higher $\sigma$ for a given $\mu$ leads to a higher average consumption after the first couple of years as individuals are more likely to stick to the guarantee.

The likelihood of making an excess withdrawal for the plain VA/GWLB is presented in Panel A of Figure 6. A lower drift $\mu$ for a given $\sigma$ leads to a lower chance of excessive withdrawals, as these become less attractive compared to the guaranteed amount. We observe a reverse S-shaped form for the probability of making an excess withdrawal, meaning that the 
probability decreases quickly early in retirement. Later, the probability decreases slower, again increasing when very close to one.

\section{Figure 6 here}

Increasing the volatility $\sigma$ for a given $\mu$ increases the likelihood of sticking to the guarantee as the GWLB becomes more variable in a more volatile market environment. Panel B illustrates the excess withdrawal probability of the ratchet VA/GWLB, and results confirm that a ratchet always decreases the likelihood of withdrawing excessively. Differences are small in the beginning, become more significant during the middle years, and almost vanish towards the end where basically all account values have been depleted and individuals rely on the remaining guaranteed withdrawal, if any. Again, a higher $\mu$ increases the probability of excessively withdrawing while a higher variance makes the guarantee more attractive. The biggest difference between the plain and the ratchet VA/GWLB is that there is a steady decrease in the excess withdrawal probability rather than the S-shape observed in the plain product case. Accordingly, the guarantee becomes more attractive during the middle years under the ratchet VA/GWLB which can be contributed mostly to the in-built step-up. From an insurer's perspective, withdrawal behavior becomes more predictable during customers' middle age when the ratchet is included.

Mortality. Next we compute the impact of using a different mortality table - the population SSN 2006 table - which includes the whole U.S. population instead of focusing only on annuity owners. To give a sense on how these tables differ, the remaining life expectancy of a male age 65 is 20.5 years under annuitant tables, while it is 17.6 years under SSN mortality. Not surprisingly, using the population tables does have an impact on the MWR of the plain VA/GWLB as well as the ratchet VA/GWLB. SSN mortality reduces the MWR ratio (with or without the ratchet) by roughly 1-2 cents per dollar; yet these differences are much less pronounced than in conventional fixed annuities where Mitchell et al. (1999) reported differences of roughly 10 cents. This is because we consistently find the pattern that 
individuals rely on the GWLB as a security buffer in the later years, where a large portion of the population is already deceased. Accordingly, differences in life expectancy do not matter as much as in traditional fixed annuities.

\section{Conclusions}

Variable annuities with guaranteed minimum lifetime withdrawal benefits (VA/GWLBs) are important retirement payout products, as they offer retirees access to an investment portfolio along with the added security of a lifetime payout annuity. We offer insights into how risk-averse individuals could rationally utilize such a VA/GWLB product, and we compare this to two different outside options, namely non-VA investment as well as a SPIA annuity. The Money's Worth Ratio we compute for the VA/GWLB without a ratchet has a MWR of 89. This implies that for each invested dollar, a buyer gives up 11 cents for the embedded protection of the VA/GWLB. Including a ratchet increases the MWR by about one cent. These figures are comparable to simpler MWRs for SPIA annuities using Social Security mortality tables. ${ }^{27}$

For a risk-averse retiree, we demonstrate that the basic VA/GWLB is unlikely to induce systematic withdrawals early in retirement, while it also provides useful protection in the case of extreme longevity. The typical VA/GWLB increases utility compared to not annuitizing, though its money's worth ratio is slightly lower. How people invest their assets within the VA does change the product's valuation, mattering much more than fees or mortality. Having a GWLB prompts riskier portfolio choices up to the point where insurers must restrict the risky share so as to protect solvency. This is especially true for the ratchet product where the enhanced GWLB becomes more worthwhile with a higher volatility. From an industry perspective, the ratchet makes policyholder behavior more predictable in terms of making systematic withdrawals.

\footnotetext{
${ }^{27}$ See Mitchell et al. (1999) and James and Song (2001).
} 


\section{References}

Abbott, L., G. Alvero, D. Brooks, D. Dunning, K. Kennedy, W. Kecken, T. Pollock and S. Wolfram (2009): Financial Product Risk Mitigation System and Method. US Patent No. US 2009/0150301.

Allianz (2012): Prospectus of the Connections Variable Annuity. Available at https://www.allianzlife.com/content/public/Literature/Documents/CNT-062-WW.pdf. Download 06/08/2012.

Bauer, D., J. Russ and A. Kling (2008): A Universal Pricing Framework for Guaranteed Minimum Benefits in Variable Annuities. Astin Bulletin, Vol. 38(2), pp. 621-651.

Brown, J.R. and J. M. Poterba (2006): Household Ownership of Variable Annuities, Tax Policy. Vol. 20, pp. 163-191.

Chai, J., W. Horneff, R. Maurer, and O.S. Mitchell (2011): Optimal Portfolio Choice over the Life Cycle with Flexible Work, Endogenous Retirement, and Lifetime Payouts. Review of Finance. 15(4), pp. 875-907.

Charupat, N. and M. A. Milvesky (2002): Optimal Asset Allocation in Life Annuities - A Note. Insurance: Mathematics and Economics. Vol. 30(2), pp. 199-209.

Coleman, T.F., Y. Kim, Y. Li and M. Patron (2007): Robustly Hedging Variable Annuities with Guarantees under Jump and Volatility Risks. Journal of Risk and Insurance. Vol. 74(2), pp. 347-376.

Dai, M., Y. Kuen Kwok and J. Zong (2008): Guaranteed Minimum Withdrawal Benefits in Variable Annuities. Mathematical Finance. Vol. 18(4), pp. 595-611.

Doyle, S., O.S. Mitchell, and J. Piggott (2004): Annuity Values in Defined Contribution Retirement Systems: Australia and Singapore Compared. Australian Economic Review, Vol. 37( 4), pp. 402-416.

Fong, Wai M. (2002): On the Cost of Adverse Selection in Individual Annuity Markets: Evidence from Singapore. Journal of Risk and Insurance. Vol. 69(2), pp. 193-207.

Fong, J.H.Y., O.S. Mitchell, and B. S. K. Koh. (2011): "Longevity Risk Management in Singapore's National Pension System.” Journal of Risk and Insurance. Vol. 78(4), pp. 961-984.

Gomes, F. and A. Michaelides (2005): Optimal Life-Cycle Asset Allocation: Understanding the Empirical Evidence. Journal of Finance, Vol. 60(2), pp. 869-904.

Holz, D., J. Russ and A. Kling (2008): GMWB for Life - An Analysis of Lifelong Withdrawal Guarantees. Ifa-Ulm working paper.

Horneff, W., R. Maurer, O.S. Mitchell, and I. Dus (2007): Following the Rules: Integrating Asset Allocation and Annuitization in Retirement Portfolios. Insurance: Mathematics and Economics. 42: 396-408.

Horneff, W., R. Maurer, O.S. Mitchell, and M. Stamos (2009): Asset Allocation and Location over the Life Cycle with Survival-Contingent Payouts. Journal of Banking and Finance. (33) 9 September: 1688-1699.

Horneff, W., R. Maurer and R. Rogalla (2010a): Dynamic Portfolio Choice with Deferred Annuities, Journal of Banking and Finance. Vol. 34, pp. 2652-2664.

Horneff, W., R. Maurer, O.S. Mitchell, and M.Z. Stamos (2010b): Variable Payout Annuities and Dynamic Portfolio Choice in Retirement. Journal of Pension Economics and Finance. 9, April: 163-183. 
Insured Retirement Institute. (IRI 2012). Variable Annuities Net Assets Reach All-time High. Available at http://www.irionline.org/news/article/id/647. Download 06/08/2012.

Insured Retirement Institute. (IRI, 2010): 2010 Annuity Factbook. Washington, DC: IRI.

Kartashov, V., R. Maurer, O. S. Mitchell, and R. Rogalla (2011): Variable and InvestmentLinked Deferred Payout Annuities (VILDAs) in Household Portfolios over the Life Cycle. Report to TIAA-CREF.

Koo, H. (1998): Consumption and Portfolio Selection with Labor Income: A Continuous Time Approach. Mathematical Finance Vol.8, pp. 49-65

Kling, A., F. Ruez and J. Russ (2010): The Impact of Stochastic Volatility on Pricing, Hedging, and Hedge Efficiency of Variable Annuity Guarantees, Ifa-Ulm working paper.

James, E. and X. Song (2001): Annuity Markets Around the World: Money's Worth and Risk Intermediation. SSRN: http://ssrn.com/abstract $=287375$

LIMRA (2010): Variable Annuity Guaranteed Living Benefit Election Tracking Survey Report, Download 01/06/2011 at http://www.limra.com/newscenter/NewsArchive/ArchiveDetails.aspx?prid=117

Maurer, R., O.S. Mitchell and R. Rogalla (2010): "The Effect of Uncertain Labor Income and Social Security on Lifecycle Portfolios." In R. Clark and O.S. Mitchell, eds. Reorienting Retirement Risk Management. Oxford: OUP, pp 107-121.

Milevsky, M.A. and S.E. Posner (2001): The Titanic Option: Valuation of the Guaranteed Minimum Death Benefit in Variable Annuities and Mutual Funds. Journal of Risk and Insurance. Vol.68(1), pp. 93-128

Milevsky, M.A. and T. S. Salisbury (2008): Financial Valuation of Guaranteed Minimum Withdrawal Benefits. Insurance: Mathematics and Economics. Vol. 38(1), pp. 21-38.

Mitchell, O.S., J.M. Poterba, M. J. Warshawsky and J.R. Brown (1999): New Evidence on the Money's Worth of Individual Annuities. American Economic Review. Vol. 89(5), pp. 1299-1318.

Orman, S. nd. "Annuities." www.suzeorman.com/igsbase/igstemplate.cfm?SRC=MD012\&SRCN=aoedetails\&GnavID $=84 \&$ SnavI $\mathrm{D}=29 \&$ TnavID $=\&$ AreasofExpertise $\mathrm{ID}=107$

Pang, G., and M. Warshawsky (2010): Optimizing the Equity-Bond-Annuity Portfolio in Retirement: The Impact of Uncertain Health Expenses. Insurance: Mathematics and Economics, Vol. 46(1), pp. 198-209.

Poterba J., S. Venti and D. Wise (2012) Were They Prepared for Retirement? Financial Status at Advanced Ages at the HRS and AHEAD Cohorts. NBER Working Paper No. 17824

Prudential (2012): New York State Prospectus of the Premier Advisor Variable Annuity. Available at http://www.prudential.com/media/managed/documents/pruannuities_investor/ppr_ny_pros.pdf?siteID= 25. Download 06/08/2012.

Smartmoney.com (2011): What's Wrong with Variable Annuities. August. http://www.smartmoney.com/retirement/planning/whats-wrong-with-variable-annuities-9512/

Social Security Administration (SSA, 2011): Monthly Statistical Snapshot. February www.ssa.gov/policy/docs/quickfacts/stat snapshot/

Society of Actuaries (SOA, 2006): Annuity 2000 Mortality Table. Available at http://soa.org 
Thorburn, C., R. Rocha, and M. Morales (2007): An Analysis of Money's Worth Ratios in Chile. Journal of Pension Economics and Finance. Vol. 6(03), pp. 287-312.

Ulm, E. (2006): The Effect of the Real Option to Transfer on the Value of Guaranteed Minimum Death Benefits. Journal of Risk and Insurance. Vol. 73(1), pp. 43-69

Ulm, E. (2010): The Effect of Policyholder Transfer Behavior on the Value of Guaranteed Minimum Death Benefits in Annuities. North American Actuarial Journal. Vol. 14(1), pp. $16-37$

Viceira, L. (2001): Optimal Portfolio Choice for Long-horizon Investors with Nontradeable Labor Income. Journal of Finance. Vol. 55, pp. 1163-1198. 
Table 1: Money's Worth Ratios (MWR) and AEWs of Different Portfolios

$\begin{array}{llll} & \underline{\text { MWR }} & & \text { AEW } \\ \text { Investment only } & 1.00 & & \$ 100,000 \\ \text { Plain VA/GWLB } & 0.89 & & \$ 107,378 \\ \text { Ratchet VA/GWLB } & 0.90 & \$ 113,782 \\ \text { SPIA 6,950\$ } & 0.81 & \$ 134,745 \\ \text { SPIA 7,950\$ } & 0.93 & \$ 165,129\end{array}$

Note: VA/GWLB refers to variable annuity with a guaranteed withdrawal lifetime benefit; with or without ratchet refers to whether there is an annual step-up if the account value is sufficiently large; SPIA is a single premium immediate annuity. See text for further discussion.

Table 2: MWR and AEW Values under Alternative Fee Assumptions

$\begin{array}{clll} & \underline{\text { MWR }} & & \text { AEW } \\ \text { Plain VA/GWLB } & & \\ \text { Base case (237 bps) } & 0.89 & & \$ 107,378 \\ \text { Low fee (129 bps) } & 0.94 & \$ 112,012 \\ \text { High fee (280 bps) } & 0.87 & \$ 105,419 \\ \text { Ratchet VA/GWLB } & & \\ \text { Base case (237 bps) } & 0.90 & \$ 113,782 \\ \text { Low fee (129 bps) } & 0.95 & \$ 118,039 \\ \text { High fee (280 bps) } & 0.88 & \$ 111,744\end{array}$

Note: See Table 1 for definitions. 
Table 3: MWR and AEW Values under Different Capital Market Scenarios

\begin{tabular}{|c|c|c|c|c|}
\hline \multirow[b]{2}{*}{$\mu=0.04$} & $\begin{array}{l}\text { Plain } \\
\text { MWR }\end{array}$ & $\begin{array}{l}\text { VA } \\
\text { AEW }\end{array}$ & Ratchet VA & $\begin{array}{l}\mathrm{t} V \mathrm{~A} \\
\mathrm{AEW} \\
\end{array}$ \\
\hline & & & & \\
\hline$\sigma=0.10$ & 0.81 & $\$ 95,997$ & 0.80 & $\$ 97,981$ \\
\hline$\sigma=0.18$ & 0.85 & $\$ 99,120$ & 0.85 & $\$ 104,968$ \\
\hline$\sigma=0.25$ & 0.88 & $\$ 99,631$ & 0.89 & $\$ 110,197$ \\
\hline$\mu=0.0675$ & & & & \\
\hline$\sigma=0.10$ & 0.87 & $\$ 106,076$ & 0.86 & $\$ 107,305$ \\
\hline$\sigma=0.18$ & 0.89 & $\$ 107,378$ & 0.90 & $\$ 113,782$ \\
\hline$\sigma=0.25$ & 0.91 & $\$ 106,581$ & 0.95 & $\$ 117,714$ \\
\hline$\mu=0.10$ & & & & \\
\hline$\sigma=0.10$ & 0.90 & $\$ 126,503$ & 0.91 & $\$ 125,510$ \\
\hline$\sigma=0.18$ & 0.91 & $\$ 121,931$ & 0.96 & $\$ 126,302$ \\
\hline$\sigma=0.25$ & 0.94 & $\$ 118,348$ & 1.01 & $\$ 128,269$ \\
\hline
\end{tabular}

Note: See Table 1 for definitions. 
Figure 1. Example of the Guarantee Development under Deterministic Withdrawal Behavior and Excess Withdrawals

\section{A: Excess Withdrawal at $t_{4}$ : Plain VA/GWLB}
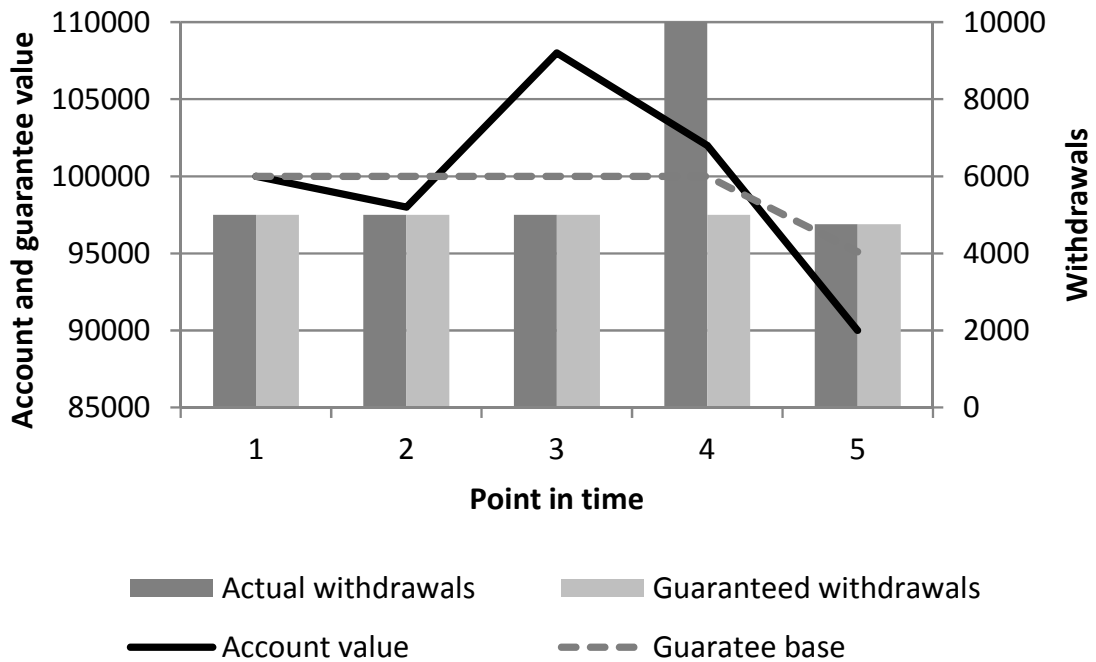

\section{B: Ratchet VA/GWLB}

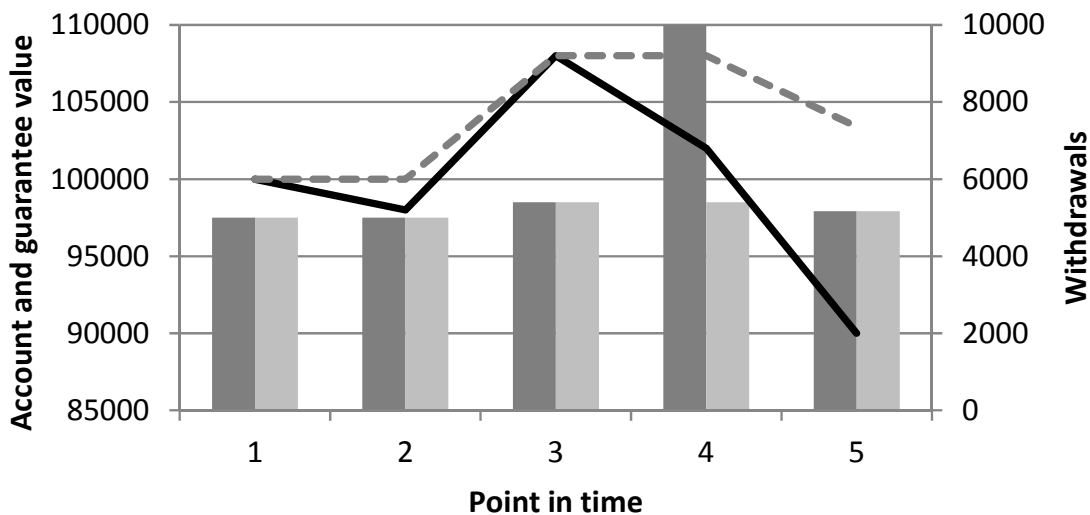

Actual withdrawals

Guaranteed withdrawals

Account value

- Guarantee base

Note: Panels A and B provide an example of how an excess withdrawal impacts the guarantee base under the plain and ratchet VA/GWLBs. We assume a deterministic withdrawal behavior, where the individual withdraws the guaranteed amount at times 1,2, 3 and 5 and makes an excess withdrawal of $\$ 10,000$ at time 4 . The dark grey column shows actual withdrawals, and the light grey column the guaranteed withdrawals. The dotted line displays the guarantee base while the solid line illustrates the account value which changes due to withdrawals and asset performance. 
Figure 2: Mean Consumption above Floor Conditional on Survival under the Three Portfolio Alternatives

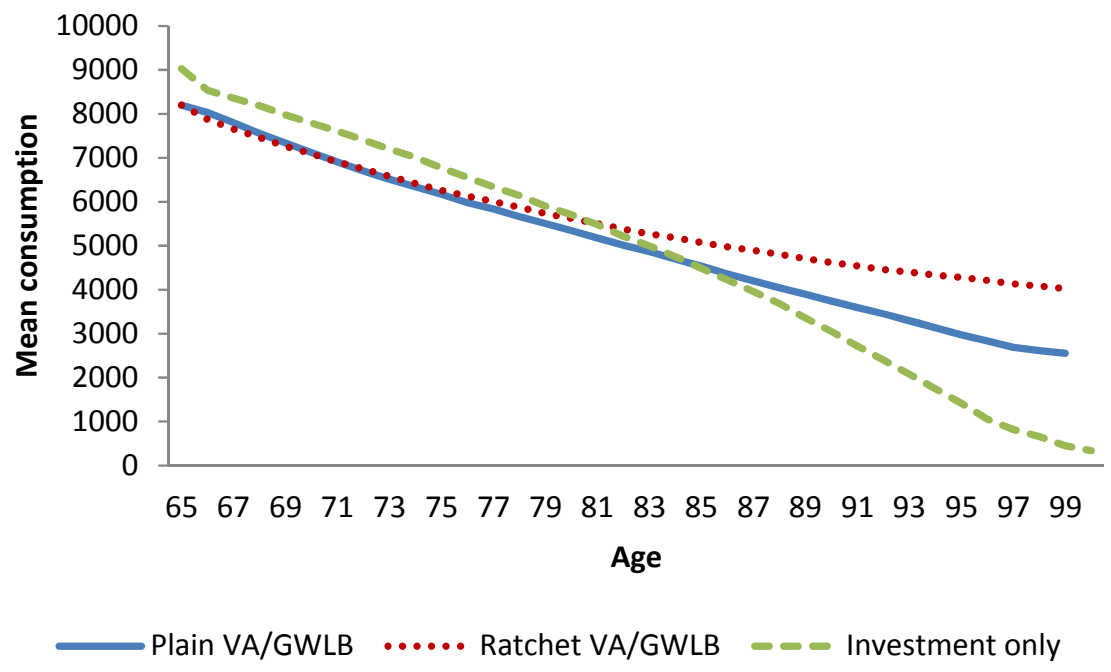

Note: Figure 2 displays mean consumption from the VA (above the Social Security benefit floor) for all individuals alive at the given age for the base case plain and ratchet VA/GWLBs, and the investment only alternative.

Figure 3: Standard Deviation of Consumption Conditional on Survival under Three Portfolio Alternatives

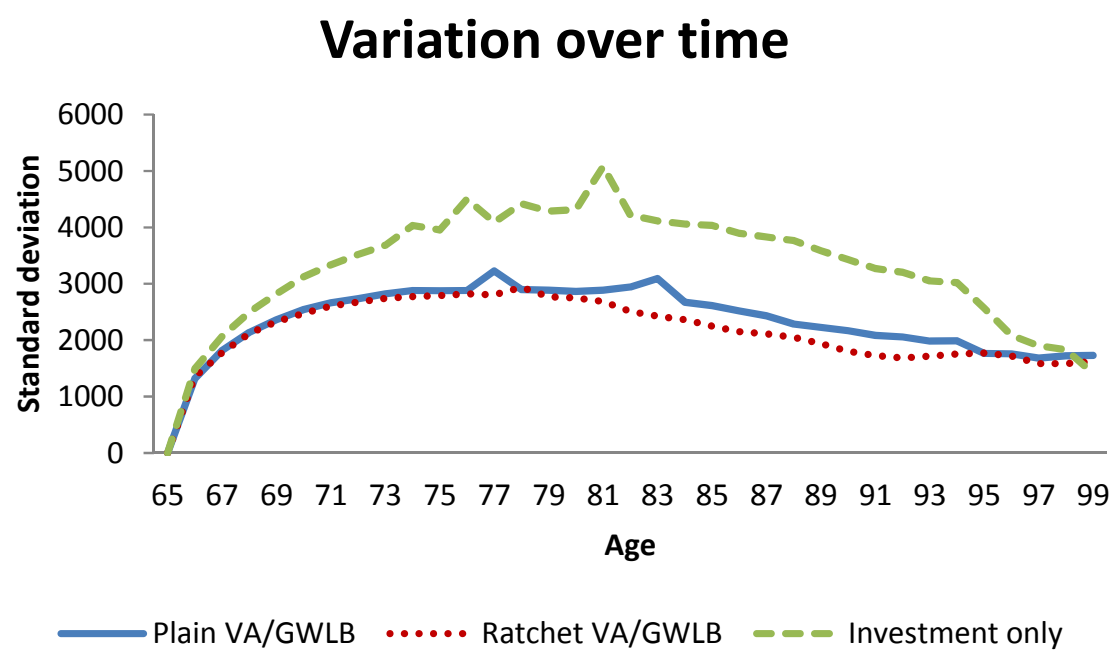

Note: Figure 3 displays the standard deviation of consumption from the VA (above the Social Security benefit floor) for individuals alive at the given age for the base case plain and ratchet VA/GWLBs, and the investment only alternative. 
Figure 4: Likelihood of Excess Withdrawals Conditional on Survival: Plain VA/GWLB and Ratchet VA/GWLB

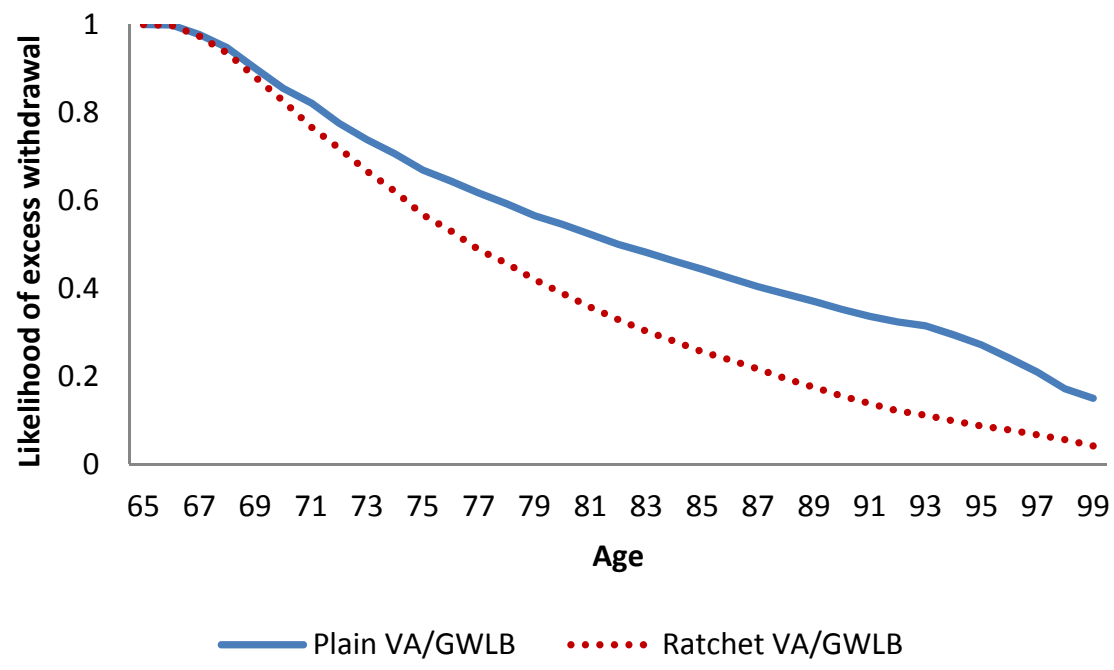

Note: Figure 4 displays the likelihood of making an excess withdrawal, i.e. withdrawing more than the guaranteed withdrawal amount, for individuals alive at the given age for the base case plain and ratchet VA/GWLBs. 
Figure 5: Mean Consumption above SSN Floor Conditional on Survival under Different Market Scenarios

\section{A. Plain VA/GWLB}

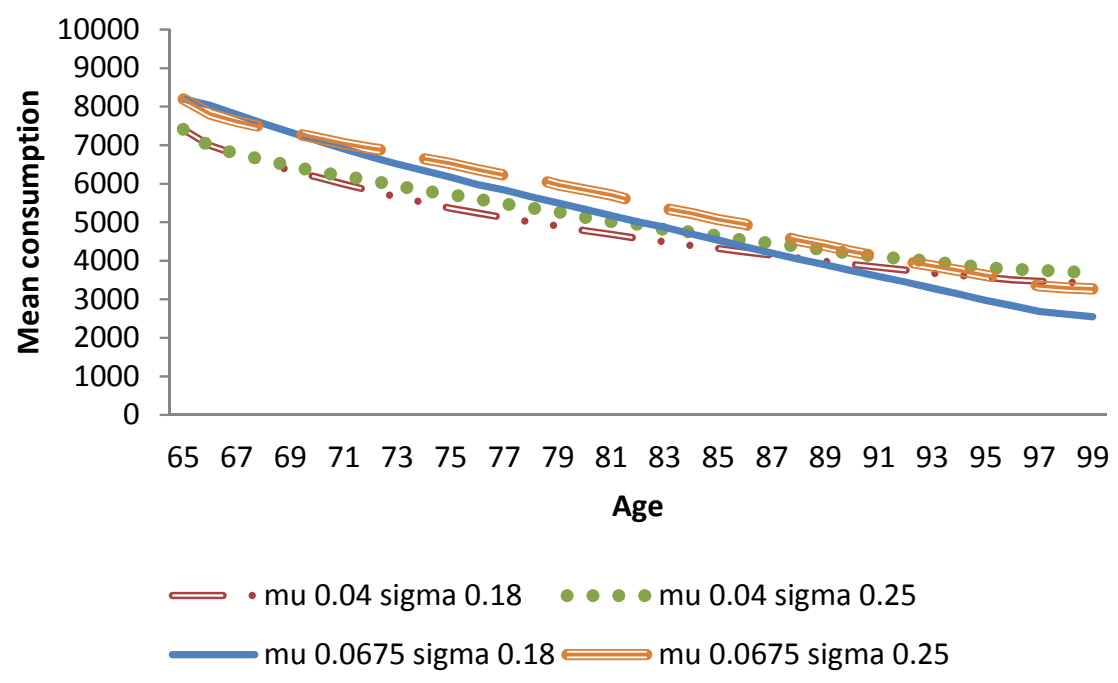

\section{B. Ratchet VA/GWLB}

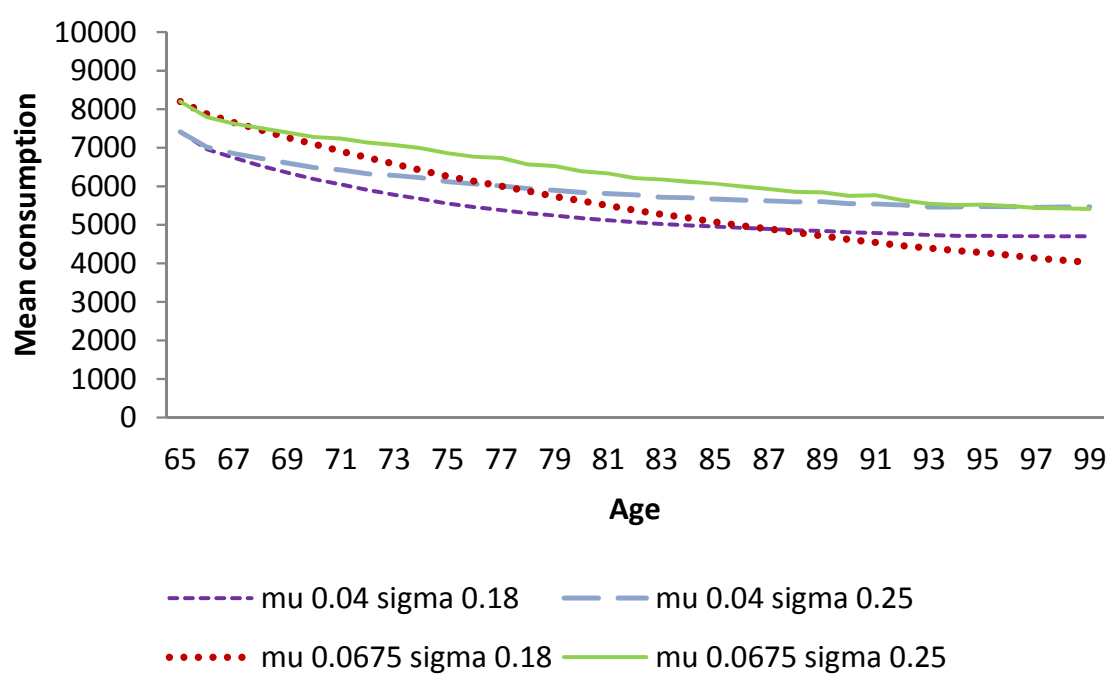

Note: Panels A and B display the mean consumption from the VA (above the SSN floor) for individuals alive at the given age for the plain and the ratchet VA/GWLBs, respectively, under different market scenarios. See text. 
Figure 6. Likelihood of Excess Withdrawal under Different Market Scenarios

\section{A. Plain VA/GWLB}

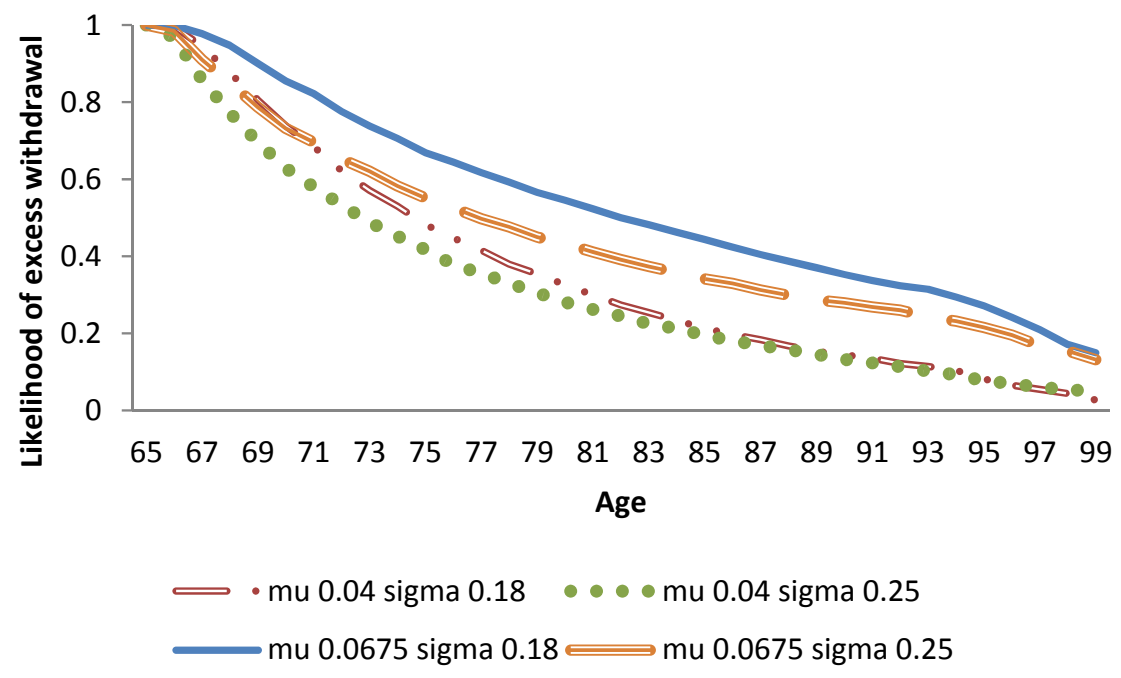

\section{B. Ratchet VA/GWLB}

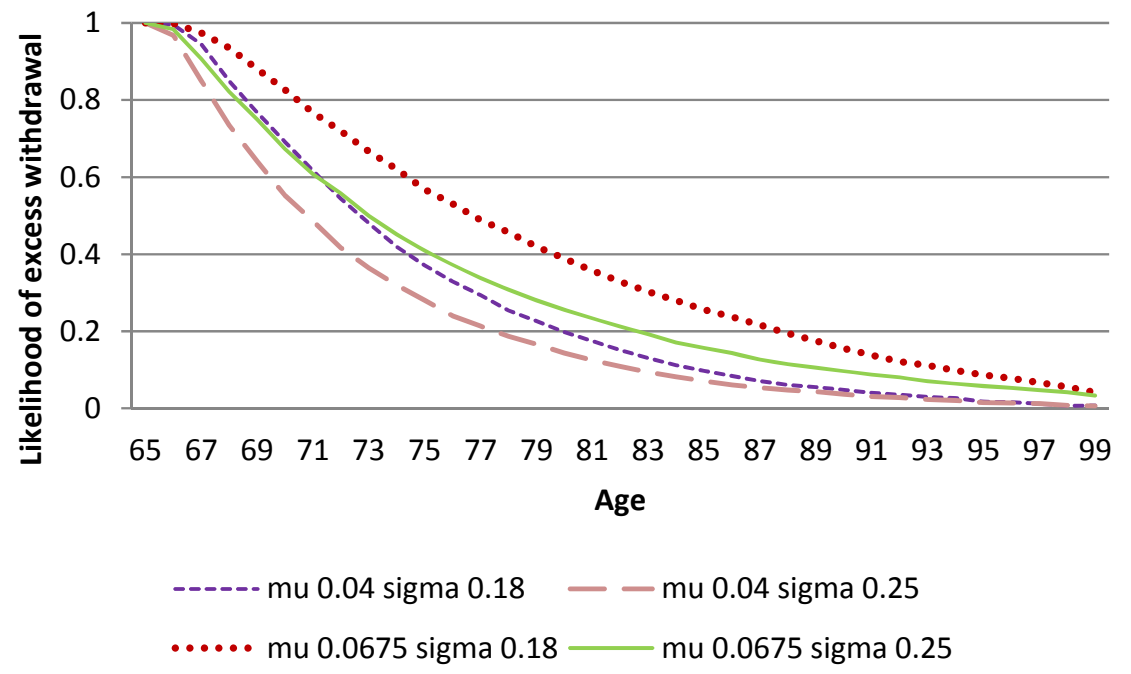

Note: Panels A and B display the likelihood of making an excess withdrawal (more than the guaranteed withdrawal) for individuals alive at the given age, for the plain and the ratchet VA/GWLBs, respectively, under different market scenarios. See text. 